\title{
Impact of International Immersion Experiences in Occupational Therapy Education: A Retrospective Survey
}

\author{
Joyce Salls \\ Chatham University, salls@chatham.edu \\ Ingrid Provident \\ Chatham University, iprovident@chatham.edu \\ Cathy Dolhi \\ Chatham University, cddotr@yahoo.com
}

Follow this and additional works at: https://nsuworks.nova.edu/ijahsp

Part of the Medicine and Health Sciences Commons

\section{Recommended Citation}

Salls J, Provident I, Dolhi C. Impact of International Immersion Experiences in Occupational Therapy Education: A Retrospective Survey. The Internet Journal of Allied Health Sciences and Practice. 2019 Jan 01;17(4), Article 11.

This Manuscript is brought to you for free and open access by the College of Health Care Sciences at NSUWorks. It has been accepted for inclusion in Internet Journal of Allied Health Sciences and Practice by an authorized editor of NSUWorks. For more information, please contact nsuworks@nova.edu. 


\title{
Impact of International Immersion Experiences in Occupational Therapy Education: A Retrospective Survey
}

\begin{abstract}
ABSTRACT

Purpose. The purpose of this study was to determine the impact of an international education experience on participants' self-perceived personal growth, international perspective, and intellectual development using a modified version of the International Education Survey (IES). Method. Seventy-one participants, representing occupational therapy practitioners and students from multiple universities, completed the survey. Results. Mean scores were highest for impact in the area of International Perspectives ( $M=5.32)$, followed by Personal Development ( $M=4.65)$, and Intellectual Development $(M=4.05)$. Additionally, $100 \%$ of the participants responded that all university students should be encouraged to engage in international education experiences $(M=6.66)$. Qualitative comments related to the impact of their experiences revealed increased awareness and appreciation for cultural differences, a feeling of personal growth, and a reshaping of both personal life priorities and professional responsibilities. Study limitations include the relatively small sample size, variability of length of participants' international experience, as well the variability in the number of immersion experiences reported. Conclusions and Recommendations. Engaging students in international immersion experiences during academic preparation had a positive impact on participants' self-perceived cultural competence. Future research should explore the impact of the length of time and number of international experiences on practitioners' perceptions of cultural competence as well as the impact of immersion experiences on professional practice.
\end{abstract}

\section{Author Bio(s)}

Joyce Salls, OTD, OTR/L, Director, Occupational Therapy, Chatham University has 30+ years' experience in occupational therapy. She has presented nationally and internationally on topics in pediatrics and education, and published in areas of school based practice and program outcomes. Dr. Salls has led service trips to Haiti, Bolivia and Ecuador.

Ingrid Provident, Ed.D, OTR/L FAOTA, Associate Professor, Post Professional OTD Coordinator, Chatham University has $30+$ years of occupational therapy practice. She has presented nationally and internationally on professional transformation and educational practice, published in the areas of fieldwork and transformative learning, and led service trips to Kenya, Tanzania, and Ecuador.

Cathy Dolhi, OTD, OTR/L, FAOTA, Faculty Emeritus, Chatham University has 35+ years' experience in occupational therapy. Clinical specialties include spinal cord injuries, prosthetics, occupation-based practice, and client-centered care. She has presented and published on multiple clinical and administrative topics and is active in local, state, and national occupation therapy organizations. 


\title{
IJAHSP \\ The Internet Journal of Allied Health Sciences and Practice \\ Dedicated to allied health professional practice and education
}

Vol. 17 No. 4 ISSN 1540-580X

\section{Impact of International Immersion Experiences in Occupational Therapy Education: A Retrospective Survey}

\author{
Joyce Salls \\ Ingrid Provident \\ Cathy Dolhi \\ Chatham University \\ United States
}

\begin{abstract}
Purpose. The purpose of this study was to determine the impact of an international education experience on participants' selfperceived personal growth, international perspective, and intellectual development using a modified version of the International Education Survey (IES). Method. Seventy-one participants, representing occupational therapy practitioners and students from multiple universities, completed the survey. Results. Mean scores were highest for impact in the area of International Perspectives $(M=5.32)$, followed by Personal Development $(M=4.65)$, and Intellectual Development ( $M=4.05)$. Additionally, $100 \%$ of the participants responded that all university students should be encouraged to engage in international education experiences $(\mathrm{M}=6.66)$. Qualitative comments related to the impact of their experiences revealed increased awareness and appreciation for cultural differences, a feeling of personal growth, and a reshaping of both personal life priorities and professional responsibilities. Study limitations include the relatively small sample size, variability of length of participants' international experience, as well the variability in the number of immersion experiences reported. Conclusions and Recommendations. Engaging students in international immersion experiences during academic preparation had a positive impact on participants' self-perceived cultural competence. Future research should explore the impact of the length of time and number of international experiences on practitioners' perceptions of cultural competence as well as the impact of immersion experiences on professional practice.
\end{abstract}

Keywords: international education, cultural competence 


\section{INTRODUCTION}

Technological innovations, pervasive social media, and accessible international travel are but a few of the factors that have contributed to the concept of globalization. The United States Census Bureau reported that the United States is expected to become a "majority-minority" nation for the first time in 2043 with minorities (including all persons except the single-race, nonHispanic white population) expected to increase from $37 \%$ to $57 \%$ of the population in $2060 .{ }^{1}$ Effective interaction with culturally diverse individuals requires that health care providers have cross cultural training. ${ }^{2,3}$

Multicultural (cultural) competency refers to the "ability to function effectively in cross- cultural interactions with clients who are from a different cultural group. ${ }^{4}$ This concept is central to the provision of client/person centered care where intervention emphasizes a "respect for and partnership with clients as active participants in the therapy process." ${ }^{5} \mathrm{An}$ appreciation for and understanding of the impact of culture on the choices made by clients is an integral characteristic of providing client centered, occupation based care in occupational therapy. The World Federation of Occupational Therapists identified three components of cultural competence (knowledge, skills, and attitude) as essential principles for ensuring culturally relevant occupational therapy practice. ${ }^{6}$ Beagan noted that "knowledge entails learning about other cultures" and skills include "effective communication, rapport building,... respect, active listening, advocacy, ... [and] use of culturally appropriate occupations...." Beagan included the concept of attitude within the construct of awareness, which refers to insight into one's own values and biases as well as developing an understanding and awareness of similar priorities in those unlike one's self.

In a systematic review of the literature, Beach et al determined that training in cultural competence improved the knowledge, skills, and attitudes of health care providers. ${ }^{8}$ The immersion of students into a new culture via a global service learning experience is an example of one method for enhancing students' cultural competence. The degree to which that strategy is effective for improving the knowledge, skills, and attitudes of students has been explored by multiple authors, but the long term impact of the experience on the participant as a practitioner is less evident in the literature. .-20 $^{9-2}$

While didactic learning may be effective for improving cultural competence, there is literature to support that the addition of a cultural immersion experience may have a greater impact. Caffrey et al and Larsen and Reif compared improvements in selfperceived cultural competence in nursing students. ${ }^{10,16}$ Both studies used a two-group, pretest- posttest, quasi-experimental design to compare outcomes in students who participated in a cultural immersion experience to those who participated exclusively in classroom training related to culturally diverse topics. Although students who were exposed to cultural content in the didactic setting experienced an overall increase in culturally competent knowledge, skills, and attitudes, mean scores for students who participated in the cultural immersion experience were greater across all three areas. Bentley and Ellison reported the findings of a study in which a group of nursing students participated in a classroom based course focusing on cultural content followed by an eight-day experiential component to Quito, Ecuador. After the didactic course, all students improved their cultural competence score with two students moving from the culturally aware to the culturally competent category on the Inventory for Assessing the Process for Cultural Competence Among Health Care Professionals-Revised 2002. ${ }^{9}$ The authors reported that "the trip had the greatest impact with 5 more of the students moving into the culturally competent category."9 Green et al used both qualitative and quantitative strategies to explore the value of an international service learning experience in nursing and medical students who visited Intibucá, Honduras, for a 10-day period. Although the participants did not engage in a didactic component, comparison of pre and post-experience assessments using the Cultural Competence Assessment tool revealed an increase in cultural competence by all participants following the immersion experience. ${ }^{13}$

In a study by Curtin et al, 11 baccalaureate nursing students participated in five pre-trip sessions prior to a two week experience in the Dominican Republic, and three post-trip sessions at the conclusion of the experience. The authors described an overall increase in participants' empathy, acceptance of differences, and communication skills, all factors associated with cultural competence. ${ }^{11}$ Keane and Provident conducted a study using on-line and face-to-face didactic experiences prior to a nine day trip to Ecuador. The six Master of Occupational Therapy and six Doctor of Physical Therapy students also completed a post trip on-line reflective assignment. Results revealed that all participants experienced an increase in cultural competence and a desire to continue intercultural practice. ${ }^{15}$

Edmonds reported on the results of a review of the literature examining study abroad programs for nursing students. As in the aforementioned studies, it was determined that cultural competence was enhanced by virtue of participation in a global learning experience. In addition, attributes such as cultural sensitivity, global awareness and understanding, comfort level, cultural awareness and respect, international perspective, and personal development were reported to be enhanced as a result of the students' international experience. ${ }^{12}$ This finding adds strength to Sandell's conclusion that "For universities that work to prepare students for the rapid changes in the world and for increasingly diverse populations, international education experiences provide important opportunities for increased global-mindedness." ${ }^{21}$ 
The previously noted studies focus on the immediate impact of a global immersion experience on student participants. The longerterm effect of the experience on the participant as a health care practitioner has been less frequently explored. Humbert et al reported the findings of interviews of nine occupational therapy students who participated in international fieldwork or service learning experiences within the prior two-year period. In addition to increasing cultural awareness, the participants reported an enhanced sense of connectedness and heightened awareness of the complexity of cross-cultural experiences as a result of their engagement. ${ }^{14}$ Kollar and Ailinger reported on 12 alumni from a nursing program who participated in a 2 week experience in Nicaragua over a six year period. The authors asked the participants to describe the impact of the experience on their personal and professional life and to provide examples. Based on the participants' responses, the authors determined that "...the long-term impact of an international nursing education experience in a developing country can leave a lasting impact on how nurses learn more about cultural competence in providing nursing care for individuals from diverse cultures."18

Like the present one, three previous studies examined the long-term impact of international learning experiences using the International Education Survey. 17,19,20 All three studies focused on alumni of nursing programs who participated in international immersion experiences. Increases in all four dimensions (professional role, international perspective, personal development, and intellectual development) of the International Education Survey were reported suggesting that the immersion experiences contributed to long term benefits that positively impacted the participants' professional practice.

Summarily, the literature supports that classroom learning is effective for increasing cultural competence in students.9,10,16 Additionally, cultural immersion experiences have been found to result in even greater increases in cultural competence as reported by the student participants. ${ }^{9,10,16}$ The literature suggests that cultural immersion experiences have a positive influence on the future practice patterns of practitioners who participated in these experiences as students. ${ }^{14,17,18,19,20}$ However, the majority of the literature on the impact of global immersion has been restricted to the nursing profession. This project sought to determine how an international education experience impacted the personal and professional perspectives of occupational therapy students and practitioners.

\section{RESEARCH QUESTIONS}

The research questions were as follows:

1. To what degree did an international education experience impact the participants' international perspective as measured by a modified version of the International Education Survey?

2. To what degree did an international education experience impact the participants' personal development as measured by a modified version of the International Education Survey?

3. To what degree did an international education experience impact the participants' intellectual development as measured by a modified version of the International Education Survey?

\section{METHODOLOGY}

A mixed methods non-experimental survey design was employed in this descriptive study. The population consisted of graduates and current students of occupational therapy programs who participated in a global service learning and/or an international fieldwork experience. Subjects were recruited by the authors through snowball methodology. The first point of contact for recruitment was the distribution of a paper survey at an annual national meeting of occupational therapy program directors and academic fieldwork coordinators. This survey asked if the institutions with whom the academic program contact persons $(n=24)$ were associated used international sites for student experiences and requested the name of the contact person who coordinated these experiences. Once these contacts were gathered, an email was sent requesting them to forward information provided by the authors explaining the purpose of the research, reminders that participation was voluntary, and an electronic Qualtrics survey link. The survey included questions related to how the participants' international experience impacted their current practice of occupational therapy. Survey questions were based on the International Education Survey modified to reflect occupational therapy language as opposed to nursing with permission from the tool's author, CeCelia Zorn. ${ }^{20}$ Additionally, the authors added a Likert question related to participants' perceptions of the inclusion of global experiences in occupational therapy programs. The survey also included an open ended question for participants to share additional information on the impact of their international service learning experience. This tool was initially designed to enable investigators to explore the impact of the global education experience on the participants' international perspective, personal development, and intellectual development. It was developed originally for nursing students and has been widely used in the literature to measure students' perceptions of international experiences. ${ }^{11,17,19}$ Research subjects in this study were given three weeks to complete the 15-20-minute survey. The academic program contact persons were requested to send a follow up reminder email one week after the initial communication in an effort to ensure survey completion. After three weeks the survey was closed and the results analyzed. This study was approved by the Institutional Review 
Board at Chatham University and granted exempt status.

Participants / Sample Description

As shown in Table 1, 71 individuals completed the survey including 35 occupational therapists, 35 occupational therapy students and 1 occupational therapy assistant. Of this group, the majority (97\%) of the respondents were female. Ages ranged between $20-$ 39 with $82 \%$ in the $20-29$ age group and $18 \%$ between $30-39$ years of age. At the time of the international immersion experience, all participants were students of occupational therapy programs in the United States of America. Length of time spent in the visiting country varied with more than half of the respondents reporting a 7-14 day experience abroad (See Table 2). Travel experiences for all participants occurred between 2000 and 2015.

Table 1. Demographics

\begin{tabular}{|c|c|c|}
\hline & Number & Percentage \\
\hline \multicolumn{3}{|l|}{ Professional Credentials } \\
\hline Occupational therapist & 35 & $49 \%$ \\
\hline Occupational therapy student & 35 & $49 \%$ \\
\hline Occupational therapy assistant & 1 & $1 \%$ \\
\hline \multicolumn{3}{|l|}{ Gender } \\
\hline Female & 69 & $97 \%$ \\
\hline Male & 2 & $3 \%$ \\
\hline \multicolumn{3}{|l|}{ Age Range } \\
\hline $20-29$ & 59 & $82 \%$ \\
\hline $30-39$ & 13 & $18 \%$ \\
\hline \multicolumn{3}{|l|}{ Race/Ethnicity } \\
\hline Caucasian & 60 & $85 \%$ \\
\hline Hispanic & 10 & $14 \%$ \\
\hline African American & 1 & $1 \%$ \\
\hline Other & 0 & 0 \\
\hline
\end{tabular}

Table 2. Length of Travel Experience ( $n=53$ respondents answered this question)

\begin{tabular}{|l|c|c|}
\hline & Number & Percentage \\
\hline Up to 14 days & 30 & $57 \%$ \\
\hline 15 to 30 days & 8 & $15 \%$ \\
\hline More than 30 days & 15 & $28 \%$ \\
\hline
\end{tabular}

\section{INTERNATIONAL SURVEY RESULTS}

Likert scale scores on the International Education Survey ranged from 1 (influenced me to a low/small degree) to 7 (influenced me to a high/large degree). The means were calculated for all questions in each of the 3 subscales investigated including: International Perspective, Personal Development, and Intellectual Development. Results from the data can be found in the tables below.

The highest impact noted in the International Perspective subscale included "influenced your understanding of occupational therapy in other countries" (6.14); "influenced your understanding of health care in other countries" (5.89), "influenced your discussions with other people about international or transcultural issues" (5.83), and "shaped and influenced how you evaluate world issues" (5.69).

Table 3. International Perspective

\begin{tabular}{|l|c|c|c|}
\hline $\begin{array}{l}\text { To what degree has your international education experience as } \\
\text { a student }\end{array}$ & Mean & SD & Range \\
\hline shaped and influenced how you evaluate world issues? & 5.69 & 1.37 & $2-7$ \\
\hline enhanced your understanding of U.S. culture? & 4.80 & 1.55 & $3-7$ \\
\hline enhanced your understanding of U.S. politics? & 3.57 & 1.73 & $1-7$ \\
\hline influenced your understanding of OT in other countries? & 6.14 & 1.07 & $5-7$ \\
\hline $\begin{array}{l}\text { influenced your understanding of healthcare in other } \\
\text { countries? }\end{array}$ & 5.89 & 1.23 & $4-7$ \\
\hline $\begin{array}{l}\text { influenced your discussions with other people about } \\
\text { international or transcultural issues? }\end{array}$ & 5.83 & 1.33 & $4-7$ \\
\hline
\end{tabular}


Highest areas of impact identified in the Personal Development subscale included "made you reassess your outlook on life in the US" (6.08); "affected your interaction with people from other cultures" (5.79); "influenced your practice of professional OT" (5.72); and "contributed to your level of self-confidence" (5.39).

Table 4. Personal Development

\begin{tabular}{|l|c|c|c|}
\hline $\begin{array}{l}\text { To what degree has your international education experience as } \\
\text { a student }\end{array}$ & Mean & SD & Range \\
\hline $\begin{array}{l}\text { affected your interaction with people from other cultures? } \\
\text { affected your travel or study abroad since graduation? }\end{array}$ & 5.79 & 1.28 & $4-7$ \\
\hline $\begin{array}{l}\text { increased the likelihood that you would practice OT in } \\
\text { another country? }\end{array}$ & 4.32 & 2.07 & $1-7$ \\
\hline $\begin{array}{l}\text { influenced your practice of professional OT? } \\
\text { made you reassess your outlook on life in the U.S.? }\end{array}$ & 5.72 & 1.19 & $2-7$ \\
\hline $\begin{array}{l}\text { affected your family decisions (spouse, parenting, living } \\
\text { arrangements, etc.)? }\end{array}$ & 3.48 & 1.25 & $3-7$ \\
\hline $\begin{array}{l}\text { affected your interpersonal relationships (friends, family, } \\
\text { neighbors)? }\end{array}$ & 3.93 & 1.98 & $1-7$ \\
\hline $\begin{array}{l}\text { influenced career decisions you have made since } \\
\text { graduation? }\end{array}$ & 3.91 & 1.99 & $1-7$ \\
\hline $\begin{array}{l}\text { facilitated an international dimension in your social or } \\
\text { religious activities? }\end{array}$ & 3.96 & 1.90 & $1-6$ \\
\hline $\begin{array}{l}\text { facilitated an international dimension in your volunteer } \\
\text { activities? }\end{array}$ & 4.30 & 1.86 & $1-6$ \\
\hline \begin{tabular}{l} 
contributed to your level of self-confidence? \\
\hline
\end{tabular} & 5.39 & 1.35 & $3-7$ \\
\hline
\end{tabular}

In the third subscale, Intellectual Development, participants rated "influenced your intellectual development" as highest (5.11).

Table 5. Intellectual Development

\begin{tabular}{|l|c|c|c|}
\hline $\begin{array}{l}\text { To what degree has your international education experience as } \\
\text { a student }\end{array}$ & Mean & SD & Range \\
\hline $\begin{array}{l}\text { affected your selection of reading materials? } \\
\begin{array}{l}\text { affected your ability to speak/read languages other than } \\
\text { English? }\end{array}\end{array}$ & 3.57 & 1.81 & $1-6$ \\
\hline $\begin{array}{l}\text { influenced your intellectual development? } \\
\text { enhanced your motivation and/or ability to learn a foreign } \\
\text { language after returning to the U.S.? }\end{array}$ & 3.11 & 2.14 & $1-7$ \\
\hline
\end{tabular}

In response to the question, "To what degree would you encourage all university students to participate in international education", $100 \%$ of the respondents indicated a score of 4 or higher, with a mean score of 6.66 . This score reflects the highest ranked item on the survey.

\section{Qualitative Analysis}

Respondents were also given the opportunity to share additional information regarding their perceptions of the impact of their international experience. Themes related to culture, personal growth, and professional responsibility were noted in their comments.

Several respondents reported an increased awareness and appreciation for cultural differences:

"It was an amazing experience that opened my eyes up to a completely different culture than my own."

"Having the opportunity to experience occupational therapy, the healthcare system, and overall culture in a different country was a wonderful learning experience."

In addition to increased awareness and appreciation for cultural differences, several respondents commented on feeling a sense 
of personal growth from the experience of traveling abroad:

"My international experience taught me the importance of cultivating and expressing curiosity rather than expert opinion." "It was one of my favorite parts of my educational experience. It gave me a much better appreciation for many things I take for granted."

"My international work as a student completely changed my outlook on life and my career."

Survey respondents also shared the impact of this experience on their work as an occupational therapy practitioner. Several commented on how the experience reshaped their priorities and increased their feeling of responsibility as a professional:

"Coming home and reflecting on this trip helped me find so many other ways that I can be of better service in my own community supporting underserved communities here."

"I learned so much about Malawian culture and values and was able to relate what I learned back into my practice as an OT." "It motivated me to have a more holistic mindset; to truly see the whole person, his/her cultural needs....The experience provided me with a sense of pride for my profession..."

\section{DISCUSSION}

The results of this study are consistent with previously cited literature that found that international immersion experiences during academic preparation have a positive impact on participants' self-perceived cultural competence. . $^{9-16}$ In comparing the outcomes of this study to previous studies that utilized the International Education Survey (see Table 6), similarities and differences are noted. The similarities are evident in the quantitative outcomes as measured by the International Education Survey. The composite mean scores in each subsection of the tool reveal that respondents reported that the immersion experience had a positive impact on their perspectives. The differences between the studies lie in the sample size and related demographics. In addition to a larger sample size ( $\mathrm{N}=71$ ), the current study included occupational therapy students and practitioners who represented various university settings whereby the others had either alumni or students from a single institution as the surveyed participant group. ${ }^{11,17,19,20}$ The participants in the current study had experiences from a larger number of countries and represented occupational therapy students and practitioners rather than nursing students and practitioners.

In a thorough review of the literature, this study is the only one which uses the International Education Survey with occupational therapy students and practitioners. ${ }^{20}$ Previous studies that demonstrated increased cultural competence were conducted exclusively with students and alumni from nursing programs.11,17,19,20 The outcomes from this study expand those findings to include occupational therapy students and alumni and confirm that these experiences increase the participants' awareness of, understanding of, and sensitivity to cultural differences. As evidenced by the outcomes in this study, these international experiences, which were incurred when they were students, had a positive impact on the participants' future professional practice. This is important as it validates that practicing therapists are able to readily understand and integrate with people of different cultures by virtue of an authentic immersion experience. Academic programs focusing on improving students' cultural competence may consider exposing students to diversity in the curriculum via fieldwork immersion experiences abroad or within local culturally diverse communities. Practitioners who have had cultural immersion experiences generally share the perspective that occupations are culturally defined which increases their understanding of client centered meaning and value.

Table 6. Comparison of Studies Utilizing the International Education Survey

\begin{tabular}{|l|c|c|c|c|c|}
\hline & $\begin{array}{c}\text { Current Study: } \\
(2019)\end{array}$ & $\begin{array}{c}\text { Zorn'20 } \\
(1996)\end{array}$ & $\begin{array}{c}\text { DeDee \& } \\
\text { Stewart17 } \\
(2003)\end{array}$ & $\begin{array}{c}\text { Smith \& Curry19 } \\
(2011)\end{array}$ & $\begin{array}{c}\text { Curtin, Martins, \& } \\
\text { Schwartz-Barcott11 } \\
(2014)\end{array}$ \\
\hline Sample Size & 71 & 27 & 38 & 36 & 11 \\
\hline $\begin{array}{l}\text { International } \\
\text { Perspective }\end{array}$ & 5.32 & 5.0 & 5.1 & 5.4 & 6.03 \\
\hline $\begin{array}{l}\text { Personal } \\
\text { Development }\end{array}$ & 4.65 & 4.4 & 4.4 & 5.3 & 6.08 \\
\hline $\begin{array}{l}\text { Intellectual } \\
\text { Development }\end{array}$ & 4.58 & 3.5 & 4.8 & 4.7 & B.4 \\
\hline Participants & $\begin{array}{c}\text { Current OT } \\
\text { Students \& OT } \\
\text { Practitioners }\end{array}$ & $\begin{array}{c}\text { Nursing } \\
\text { Alumni }\end{array}$ & Nursing Alumni & Nursing Alumni & $\begin{array}{c}\text { Baccalaureate } \\
\text { Nursing Students }\end{array}$ \\
\hline Location & $\begin{array}{c}\text { Varied (15 different } \\
\text { countries) }\end{array}$ & $\begin{array}{c}\text { England, } \\
\text { Denmark, }\end{array}$ & $\begin{array}{c}\text { Brussels, Paris, } \\
\text { London }\end{array}$ & Ecuador & Dominican Republic \\
\hline
\end{tabular}

(C) The Internet Journal of Allied Health Sciences and Practice, 2019 


\begin{tabular}{|l|c|c|c|c|c|}
\hline & $\begin{array}{c}\text { Scotland, } \\
\text { Russia }\end{array}$ & & \\
\hline $\begin{array}{l}\text { Length of } \\
\text { Experience }\end{array}$ & $\begin{array}{c}\text { Up to 14 days } \\
\text { through over 30 } \\
\text { days }\end{array}$ & $\begin{array}{c}2 \text { wks }-16 \\
\text { weeks }\end{array}$ & 2 weeks & 2 weeks & 2 weeks \\
\hline Year of Graduation & $2000-2015$ & $1979-1993$ & 5 years Previous & $1999-2008$ & 2013 \\
\hline
\end{tabular}

\section{LIMITATIONS}

Although this study's sample size was larger than other studies addressing the impact of international education on perceived cultural competence, it was still relatively small, thereby, limiting generalizability. Use of the snowball methodology prohibited the researchers from knowing how many of the initial 24 contacts actually forwarded the survey to potential participants.

Because the duration of the international experience varied from as little as one week to up to several months, it is not clear if length of experience influenced responses. Likewise, some participants reported participating in more than one international experience making it unclear as to whether or not multiple experiences impacted the participants' responses. Variable length of time from when the experience occurred to the time of the survey which ranged from 2 to more than 10 years may also have affected participants' recall. Additionally, self-perceptions of cultural competence may not directly correlate with actual professional practice.

The International Educational Survey while a widely used outcome measure, provides only likert-scale quantitative data. This measure does not capture the rich qualitative information that could add to the literature by describing the impact of cultural relativism on the participants' perspective.

\section{CONCLUSIONS AND RECOMMENDATIONS}

Providing high quality occupational therapy intervention requires an understanding of diverse cultural beliefs, attitudes, and practices. This is consistent with the American Occupational Therapy Association "Vision 2025," which calls for occupational therapy to provide culturally responsive services. ${ }^{22}$ In our increasingly connected global world, cross-cultural learning experiences have been identified as an important component of professional practice. Qualitative and quantitative results of this study are consistent with those in previous literature suggesting that international learning experiences positively influence an individual's personal, intellectual, and international perspective. This study further contributes by virtue of its larger sample size and the fact that the occupational therapy participants represented more than one academic setting and included both students and practitioners. Future research should explore the impact of the length of time of an immersion experience as well as the number of experiences on both practitioners' perceived cultural competence and professional practice. Additionally, a study design that would include participants' perceptions pre and post cultural immersion experience could add to the literature. Although these international immersion experiences are time and labor intensive, costly, and may have risks associated with them, there is evidence that they are effective for enhancing the cultural competence of students and impacting future professional practice.

\section{References}

1. United States Census Bureau. U.S. Census Bureau projections show a slower growing, older, more diverse nation a half century from now. United States Census Bureau website.

www.census.gov/newsroom/releases/archives/population/cb12-243.html. Updated December 12, 2012. Accessed September 25, 2017.

2. Aldrich RM, Grajo LC. International educational interactions and students' critical consciousness: A pilot study. American Journal of Occupational Therapy. 2017;71(5):7105230020p1-7105230020p10. doi:10.5014/ajot.2017.026724.

3. Smedley BD, Stith AY, Nelson AR, editors. Unequal Treatment: Confronting Racial and Ethnic Disparities in Health Care. Washington, DC: National Academies Press; 2003.

4. American Occupational Therapy Association. Cultural competency toolkit. The American Occupational Therapy Association, Inc. website. www.aota.org/Practice/Manage/Multicultural/Cultural-Competency-Tool-Kit.aspx.

5. American Occupational Therapy Association. Occupational therapy practice framework: Domain and process (3rd ed.). American Journal of Occupational Therapy. 2014;68(Suppl. 1):S1-S48. doi:10.5014/ajot.2014.682006.

6. World Federation of Occupational Therapists. WFOT position statement: Diversity and culture. World Federation of Occupational Therapists website. www.wfot.org/ResourceCentre.aspx. Updated 2010. Accessed June 5, 2017.

7. Beagan BL. Approaches to culture and diversity: A critical synthesis of occupational therapy literature. Canadian Journal of Occupational Therapy. 2015;8(5):272-282. 
8. Beach MC, Price EG, Gary TL, et al. Cultural competency: A systematic review of health care provider educational interventions. Med Care. 2005;43(4);356-373.

9. Bentley R, Ellison KJ. Increasing cultural competence in nursing through international service-learning experiences. Nurse Educator. 2007;32(5):207-211.

10. Caffrey RA, Neander W, Markle D, Stewart B. Improving the cultural competence of nursing students: Results of integrating cultural content in the curriculum and an international immersion experience. Journal of Nursing Education. 2005;44(5):234-241.

11. Curtin AJ, Martins DC, Schwartz-Barcott D. A mixed methods evaluation of an international service learning program in the Dominican Republic. Public Health Nursing. 2015;32(1):58-67.

12. Edmonds ML. An integrative literature review of study abroad programs for nursing students. Nursing Education Perspectives. 2012;33(1):30-34.

13. Green SS, Comer L, Elliot L, Neubrander, J. Exploring the value of an international service learning experience in Honduras. Nursing Education Perspectives. 2011;32(5):302-307.

14. Humbert TK, Burket A, Deveney R, Kennedy K. Occupational therapy student perspectives regarding international cross-cultural experiences. Australian Occupational Therapy Journal. 2012;59(3):225-234.

15. Keane $E$, Provident I. Combining online education with international service learning to increase cultural competence. The Internet Journal of Allied Health Sciences and Practice. 2017;15(3):Article 6.

16. Larsen $R$, Reif $L$. Effectiveness of cultural immersion and culture classes for enhancing nursing students' transcultural self-efficacy. Journal of Nursing Education. 2011;50(6):350-354.

17. DeDee LS, Stewart $S$. The effect of student participation in international study. Journal of Professional Nursing. 2003;19(4):237-242.

18. Kollar SJ, Ailinger RL. International clinical experiences: Long-term impact on students. Nurse Educator. 2002;27(1):28-31.

19. Smith $\mathrm{K}, \mathrm{Curr}, \mathrm{K}$. Is it worth it? Measuring the long-term effects of an international experience for nursing students in Ecuador. Journal of Community Health Nursing. 2011;28(1):14-22.

20. Zorn $\mathrm{C}$. The long-term impact on nursing students of participating in international education. Journal of Professional Nursing. 1996;12(2):106-110.

21. Sandell EJ. Impact of international education experiences on undergraduate students. Delta Kappa Gamma Bulletin. 2007;73(4):12-39.

22. American Occupational Therapy Association. Vision 2025. American Journal of Occupational Therapy. 2017;71(2):7103420010. doi:10.5014/ajot.2017.713002. 